\title{
ARSITEKTUR APLIKASI MOBILE COMMERCE UNTUK MICRO ENTERPRISE
}

\author{
Marissa Utami ${ }^{1}$, Kusrini ${ }^{2}$, M. Rudyanto Arief $^{3}$ \\ ${ }^{1}$ Program Studi Teknik Infomatika, Fakultas Teknik, Universitas Muhammadiyah Bengkulu \\ Jl. Bali, Kota Bengkulu, 38119 INDONESIA \\ (telp: 0736-22765; fax: 0736-26161) \\ 1,2,3 Magister Teknik Informatika, Program Pasca Sarjana, Universitas AMIKOM Yogyakarta \\ Jl. Ringroad Utara, Condong Catur, Sleman, Yogyakarta \\ Telp: (0274) 884201-207 Fax: (0274) 884208 Kodepos: 55283 \\ E-Mail: amikom@amikom.ac.id \\ 1aisyah.putri.24@gmail.com \\ 2 kusrini@amikom.ac.id \\ ${ }^{3}$ rudy@amikom.ac.id
}

\begin{abstract}
Abstrak: Mayoritas jenis usaha di indonesia adalah dari golongan usaha mikro yang terlihat dari persentase perkembangan pada tahun 2012 yang mencapai 98,79\% dari 99,99\% atau 55,9 juta usaha mikro dari 56,5 juta Usaha Mikro, Kecil dan Menengah (UMKM) yang ada di Indonesia. Namun, minimnya dukungan teknologi mobile atau yang dikenal dengan mobile commerce akan menyulitkan perkembangan micro enterprise. Mengingat pentingnya penerapan teknologi mobile commerce pada micro enterprise, maka perlu membuat acuan, panduan dan rencana yang jelas bagi pengembangan aplikasi mobile commerce secara keseluruhan untuk micro enterprise. Pemodelan arsitektur mobile commerce dipetakan menjadi arsitektur data, arsitektur aplikasi dan arsitektur teknologi. Pengujian model arsitektur dilakukan oleh enam responden dengan menggunakan Enterprise Architecture Score Card (EA Score Card) dengan hasil perhitungan 57,56\% yang berarti arsitektur tersebut dinyatakan layak.
\end{abstract}

Kata kunci: mobile commerce, arsitektur, micro enterprise, EA Score Card

Abstract: Most of enterprise types are identified as micro enterprise. Total of microenterprise is about 55.9 billion (98.79\%) from 56.5 billion of Micro, Small, Medium Enterprises (MSMEs) in Indonesia. However, lack of mobile technology support will inhibit micro enterprise development. To tackle this problem, architecture of mobile commerce must be constructed to support micro enterprise development. Architecture is divided into three views, i.e. data architecture, application architecture and technology architecture. To validate a whole of architecture is utilized Enterprise Architecture Score Card (EA Score Card) by gathering feedback from six respondents that have expertise in e-Business, software architecture and mobile application. As the result, the architecture of mobile commerce is obtained score $57.56 \%$ that can be stated that the architecture is feasible.

Keywords: mobile commerce, architecture, micro enterprise, EA Score Card.

\section{Pendahuluan}

Pada tahun 2014 untuk usaha mikro dan kecil di Provinsi Bengkulu mengalami peningkatan sebesar 9,18\% dari tahun sebelumnya [1] dan untuk Kota Bengkulu persentase jumlah usaha pada rekapitulasi data UMKM Kota Bengkulu tahun 2016 yaitu usaha mikro sebanyak 55,1\% dari jumlah keseluruhan usaha yang ada di Kota Bengkulu [2]. Dalam hal ini, usaha mikro sama pengertiannya dengan micro enterprise [3]

Menurut Sudaryanto dan Hanim (2002), UMKM menghadapi banyak sekali permasalahan, yaitu terbatasnya modal kerja, sumber daya 
manusia yang rendah dan minimnya penguasaan ilmu pengetahuan serta teknologi [4].

Minimnya penguasaan ilmu pengetahuan serta teknologi akan menyulitkan perkembangan micro enterprise karena salah satu faktor yang dapat mendukung pengembangan bisnis adalah pemanfaatan teknologi mobile atau yang dikenal dengan mobile commerce [5], [6].

Mobile commerce adalah pengembangan dari e-commerce yang dapat membawa penjual dan pembeli bersama-sama bertransaksi dengan mudah, kapan saja dan dimana saja sehingga memungkinkan untuk mendapatkan laba yang lebih besar karena menghemat biaya serta hubungan keduanya menjadi lebih dekat [7]. Berdasarkan hasil studi literatur, penerapan teknologi mobile pada micro enterprise perlu memperhatikan alur proses bisnis [8].

Penelitian yang dilakukan oleh Setiawan (2016) adalah membuat rancangan arsitektur enterprise menggunakan 6 aspek development process dan 3 panduan matriks yaitu what, how dan where dari kerangka Zachman yang fokus pada pembangunan arsitektur sistem informasi [9]. Kolici, et.al (2013) menganalisis arsitektur aplikasi small and medium size enterprises yang sudah ada dan mencoba untuk membuat pengembangan arsitektur aplikasi mobile commerce yang lebih mendukung aktivitas small and medium size enterprises [10].

Untuk memastikan potensi atau seberapa baik arsitektur memenuhi tujuan kualitas dari dibangunnya arsitektur, digunakan sebuah metode pengujian arsitektur yaitu Enterprise Architecture Score Card (EA Score Card). Pada EA Score Card terdapat pertanyaan penilaian untuk pengujian model arsitektur mobile commerce.

\section{LANDASAN TEORI}

\section{A. Enterprise Architecture}

Enterprise architecture atau lebih dikenal dengan arsitektur enterprise merupakan suatu pekerjaan dan praktek manajemen yang dilakukan untuk meningkatkan kinerja dari suatu enterprise yaitu dengan cara membuat perusahaan tersebut mampu dalam mengintegrasikan secara keseluruhan strategi, proses bisnis, alur informasi, serta sumberdaya teknologi yang digunakannya [11].

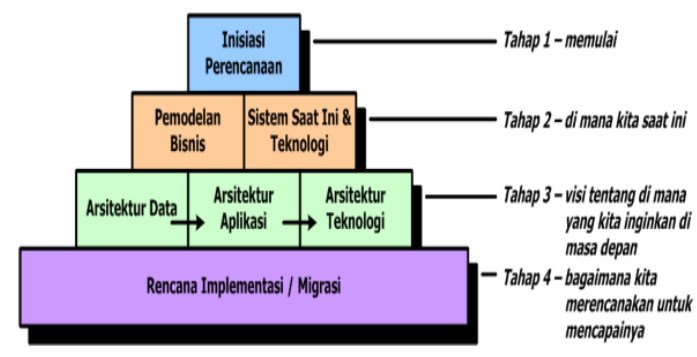

Gambar 1 Komponen Perencanaan Arsitektur Enterprise [11]

\section{B. Zachman Framework}

Ada beragam jenis framework yang dapat menunjukkan perkembangan konsep dari architecture enterprise seperti Zachman Framework, Federal Enterprise Architecture Framework (FEAF), DoD Architecture Framework (DoDAF), Treasury Enterprise Architecture Framework (TEAF), serta The Open Group Architecture Framework (TOGAF).

Menurut survei yang dilakukan oleh Institute For Enterprise Architecture Development (IFEAD) pada tahun 2005 menerangkan bahwa framework yang banyak digunakan dalam dunia industri dan pemerintahan adalah Zachman Framework, TOGAF dan FEAF dengan persentase tertinggi dimiliki oleh Zachman Framework sebesar 25\% [12], seperti yang terlihat pada Gambar 2. 
Jurnal Pseudocode, Volume IV Nomor 2, September 2017, ISSN 2355-5920 www.ejournal.unib.ac.id/index.php/pseudocode

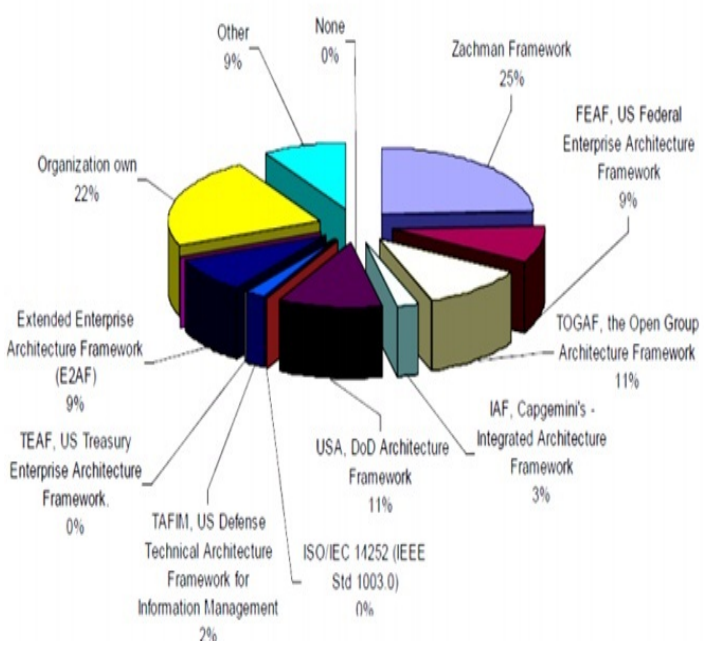

Gambar 2 Hasil Survei Pemakaian Framework [12]

Zachman Framework merupakan kerangka kerja yang berupa matriks 6x6 yang menjelaskan 6 baris perspektif atau sudut pandang, yaitu [12]:

1. Scope/Planner - memahami business scope dan dapat menyediakan view kontekstual dari enterprise.

2. Enterprise Model/Owner - memahami bisnis model dan dapat menyediakan view conceptual dari enterprise.

3. System Model / Designer - membangun model sistem yang dapat menyediakan logical view dari enterprise

4. Technology Constrained Model/Builder menghasilkan model teknologi yang dapat menyediakan physical view dari enterprise
5. Detailed Representations/Subcontractor memahami representasi detail dari spesifik item bisnis

6. Functioning Enterprise - menyediakan view functioning enterprise dari perspektif user

Selain 6 baris sudut pandang diatas pada Zachman Framework terdapat juga 6 kolom pertanyaan yang menyajikan fokus arsitektur, yaitu [12]:

1. What /Data - Apakah yang menjadi data bisnis, informasi bisnis atau objek?

2. How/Fungsi - Bagaimana bisnis berjalan / Bagaimana proses dari sebuah bisnis?

3. Where/Jaringan - Dimanakah bisnis beroperasi?

4. Who/Manusia - Siapa orang-orang yang menjalankan bisnis, unit-unit bisnis dan hirarki bisnisnya?

5. When / Waktu - Kapan proses bisnis dilakukan?

6. Why / Motivasi - Mengapa proses, pelaku atau lokasi dipandang penting dalam bisnis?

Pertemuan dari 6 baris sudut pandang dan 6 kolom pertanyaan yang ada pada Zachman Framework disebut sebagai ruang lingkup sel, seperti yang terlihat pada Gambar 3 yang menyajikan aspek-aspek yang perlu diidentifikasi dan dikelompokkan sesuai dengan baris dan kolom yang terkait [9]. 
Jurnal Pseudocode, Volume IV Nomor 2, September 2017, ISSN 2355-5920 www.ejournal.unib.ac.id/index.php/pseudocode

\begin{tabular}{|c|c|c|c|c|c|c|}
\hline $\begin{array}{l}\text { abstractior } \\
\text { perspecthers }\end{array}$ & $\begin{array}{l}\text { DATA } \\
\text { What }\end{array}$ & $\begin{array}{l}\text { FUNC IION } \\
\text { How }\end{array}$ & $\begin{array}{l}\text { NETWOFK } \\
\text { Where }\end{array}$ & $\begin{array}{c}\text { PEOPLE } \\
\text { Who }\end{array}$ & $\begin{array}{l}\text { TWRE } \\
\text { When }\end{array}$ & $\begin{array}{c}\text { BOTIVATION } \\
\text { Why }\end{array}$ \\
\hline $\begin{array}{l}\text { SCOPE } \\
\text { Plamber } \\
\text { consenoual }\end{array}$ & $\begin{array}{l}\text { List of Things - } \\
\text { important to the } \\
\text { Business }\end{array}$ & $\begin{array}{c}\text { List or Processes } \\
\text { the Business } \\
\text { Perfoms }\end{array}$ & $\begin{array}{l}\text { Last of Locations - } \\
\text { in which the } \\
\text { Buswiness Opevated }\end{array}$ & $\begin{array}{l}\text { Oitor } \\
\text { Organizations - } \\
\text { Amoortant so the } \\
\text { Busine }\end{array}$ & $\begin{array}{l}\text { List of Events - } \\
\text { Significant to the } \\
\text { Business }\end{array}$ & $\begin{array}{l}\text { Listol } \\
\text { Business } \\
\text { Goals and } \\
\text { Stra ms }\end{array}$ \\
\hline $\begin{array}{l}\text { ENTERPRISE } \\
\text { MODEL } \\
\text { Owner } \\
\text { conceptual } \\
\end{array}$ & mantic & $\begin{array}{l}\text { e.g., Business } \\
\text { Process Model }\end{array}$ & e.g., & $\begin{array}{c}\text { e.9. Work Flow } \\
\text { Model } \\
\text { a }\end{array}$ & $\begin{array}{l}\text { e.g. Master } \\
\text { Schedule }\end{array}$ & e.g. \\
\hline $\begin{array}{l}\text { SYSTEM } \\
\text { MODEL } \\
\text { Designer } \\
\text { logical }\end{array}$ & $\begin{array}{l}\text { e.9. Logical } \\
\text { Data Model }\end{array}$ & $\begin{array}{l}\text { e.g., Application } \\
\text { Archifecture }\end{array}$ & $\begin{array}{l}\text { e.g. Dis } \\
\text { Syst } \\
\text { Archit }\end{array}$ & $\begin{array}{l}\text { e.9. Human } \\
\text { Interface } \\
\text { Archigctare }\end{array}$ & $\begin{array}{l}\text { e.9. Processing } \\
\text { Structure }\end{array}$ & $\begin{array}{r}\text { e.g. B } \\
\text { Rule } \\
\text { की } \\
\text { कृ }\end{array}$ \\
\hline $\begin{array}{l}\text { TECHINOLOOY } \\
\text { CONSTRAINED } \\
\text { MODEL } \\
\text { Bullber } \\
\end{array}$ & $\begin{array}{l}\text { e.g., Physical } \\
\text { Data Model }\end{array}$ & $\begin{array}{c}\text { e.g., 8ystem } \\
\text { Design }\end{array}$ & $\begin{array}{l}\text { e.g. Technical } \\
\text { Auchistecture }\end{array}$ & $\begin{array}{l}\text { e.9. Presentatior } \\
\text { Architecture }\end{array}$ & $\begin{array}{l}\text { e.g. Control } \\
\text { Structure }\end{array}$ & e.g.R \\
\hline $\begin{array}{l}\text { DETAILED } \\
\text { REPRESEN- } \\
\text { TATIONS } \\
\text { Subcontractor } \\
\text { out-of-çontent }\end{array}$ & $\begin{array}{l}\text { e.g. Data } \\
\text { Definition }\end{array}$ & e.g. Program & $\begin{array}{l}\text { e.g. Network } \\
\text { Architecture }\end{array}$ & $\begin{array}{l}\text { e.g. Security } \\
\text { Afchitecture }\end{array}$ & $\begin{array}{l}\text { e.g. Timing } \\
\text { Definition }\end{array}$ & $\begin{array}{l}\text { e.g. Rule } \\
\text { Specification } \\
\text { 플 }\end{array}$ \\
\hline \begin{tabular}{|l|} 
FUNCOIONINO \\
ENMTERPRISE \\
\end{tabular} & $\begin{array}{c}\text { DA TA } \\
\text { Implomentation } \\
\end{array}$ & $\begin{array}{l}\text { FUTC TIOH } \\
\text { Implamentation }\end{array}$ & $\begin{array}{l}\text { NETWOFKK } \\
\text { Imalemiontation }\end{array}$ & $\begin{array}{l}\text { Artion } \\
\text { Atation }\end{array}$ & $\begin{array}{c}\text { SCHEDULE } \\
\text { Implomentation }\end{array}$ & $\begin{array}{l}\text { TEGY } \\
\text { entation }\end{array}$ \\
\hline
\end{tabular}

Gambar 3 Zachman Framework [9]

\section{Mobile Commerce}

Mobile commerce (m-commerce) merupakan pengembangan dari perdagangan elektronik ( $e$ commerce) yang secara umum merupakan suatu pertukaran elektronik (pengiriman atau transaksi) tentang informasi, barang-barang, dan pembayaran diatas jaringan telekomunikasi [7].

Mobile commerce memiliki keuntungan maupun kerugian sebagai berikut [7]:

1. Beberapa keuntungan mobile commerce, yaitu:

a) Kepuasan pelanggan, penghematan biaya, dan munculnya peluang bisnis baru.

b) Menggunakan mobile commerce setiap waktu dan dimana saja.

c) Pemilik tunggal mempunyai pengendalian atas data sehingga mobile

d) Device dapat diselaraskan.

e) Mobile commerce dapat membawa penjual dan pembeli bersama-sama bertransaksi dengan mudah sehingga memungkinkan untuk mendapatkan laba yang lebih besar serta hubungan keduanya menjadi lebih dekat.

2. Adapun beberapa kerugian mobile commerce yaitu:

a) Mobile device tidak bisa menawarkan grafik atau daya proses layaknya PC.

b) Layar yang kecil dari mobile device membatasi kompleksitas aplikasi.

\section{Enterprise Architecture Score Card}

EA Score Card merupakan alat pengukur kelayakan persiapan penerapan perencanaan enterprise arsitektur. Pengukuran yang dilakukan dalam metode EA Score Card berfokus pada proses aktivitas suatu organisasi atau perusahaan, data, aplikasi dan teknologi yang berkaitan [1].

Tabel EA Score Card yang dikembangkan oleh Schekkerman (2006) memiliki 3 definisi status yaitu [1]:

1. “ $0 "$ = Unclear, tidak teridentifikasi, tidak terdefinisikan, tidak dikumentasikan

2. " $1 "=$ Partially Clear, sudah diidentifikasi, sudah didefinisikan, ada dokumentasi 
Jurnal Pseudocode, Volume IV Nomor 2, September 2017, ISSN 2355-5920 www.ejournal.unib.ac.id/index.php/pseudocode

3. "2" = Clear, diidentifikasi dan didefinisikan dengan jelas dengan dokumentasi yang sesuai

Tabel EA Score Card memiliki kriteria hasil pengujian, yaitu [1]:

1. Jika hasil pengujian kematangan arsitektur secara keseluruhan yang dicapai $<50 \%$ maka arsitektur dinyatakan "Tidak Layak”
2. Jika hasil pengujian kematangan arsitektur secara keseluruhan yang dicapai > 50\% maka arsitektur dinyatakan "Layak”

\section{Metodologi PenELITIAN}

Penelitian ini menggunakan 3 layer pada EAP yang berbasis pada Zachman Framework dengan 6 sudut pandang dan 3 kolom pertanyaan yaitu what, how dan where. Sehingga alur penelitian dapat dilihat pada Gambar 4.

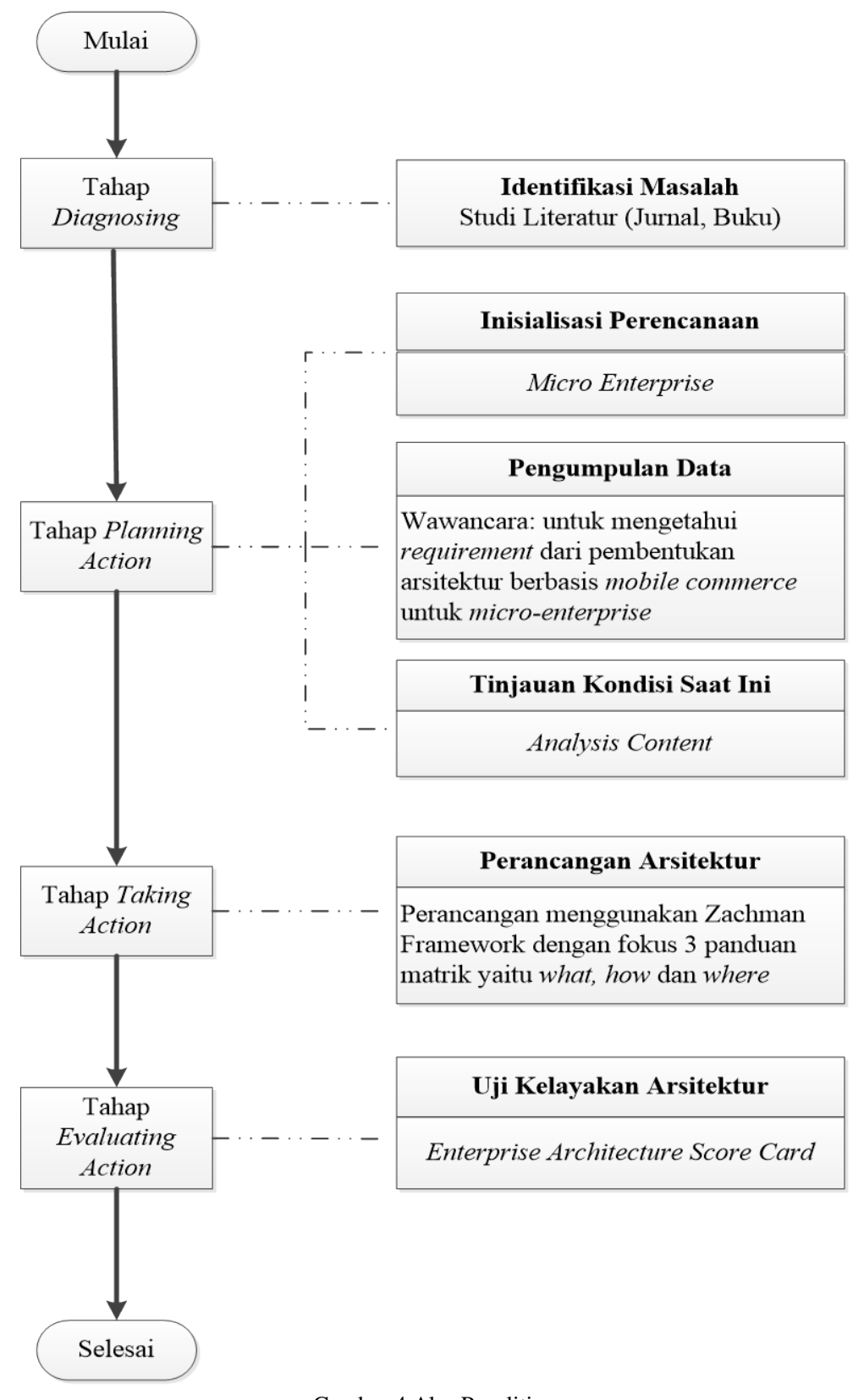

Gambar 4 Alur Penelitian 
Jurnal Pseudocode, Volume IV Nomor 2, September 2017, ISSN 2355-5920 www.ejournal.unib.ac.id/index.php/pseudocode

\section{HASIL DAN PEMBAHASAN}

Berdasarkan hasil pengumpulan data selanjutnya dilakukan tahapan pembentukan arsitektur sesuai kerangka Zachman yang akan digunakan untuk menghasilkan rancangan sistem yang dibutuhkan.

\section{A. Arsitektur Data (Kolom What)}

Menjelaskan tentang data dari sudut pandang Planner, Owner, Designer, Builder, Detailed Representation, dan Function Enterprise.

Dari sudut pandang planner data-data yang diperlukan adalah data pembeli, data penjual, data transaksi. Dari sudut pandang owner, model bisnis atau konseptual dapat dilihat dari Gambar 5.

Dari sudut pandang designer yang terlihat pada Tabel 1 didapatkan 16 entitas data menjadi ruang lingkup entitas data yang terlibat pada proses bisnis micro enterprise.

Tabel 1 Data Entitas

\begin{tabular}{|l|l|}
\hline Pembeli & Login \\
\hline Season & Pembayaran \\
\hline Keranjang Belanja & Produk \\
\hline FAQ & Language \\
\hline Register & Penjual \\
\hline Pembelian & Laporan Pembelian \\
\hline Detil Pembelian & Pengiriman \\
\hline Status Stok & Testimoni \\
\hline
\end{tabular}

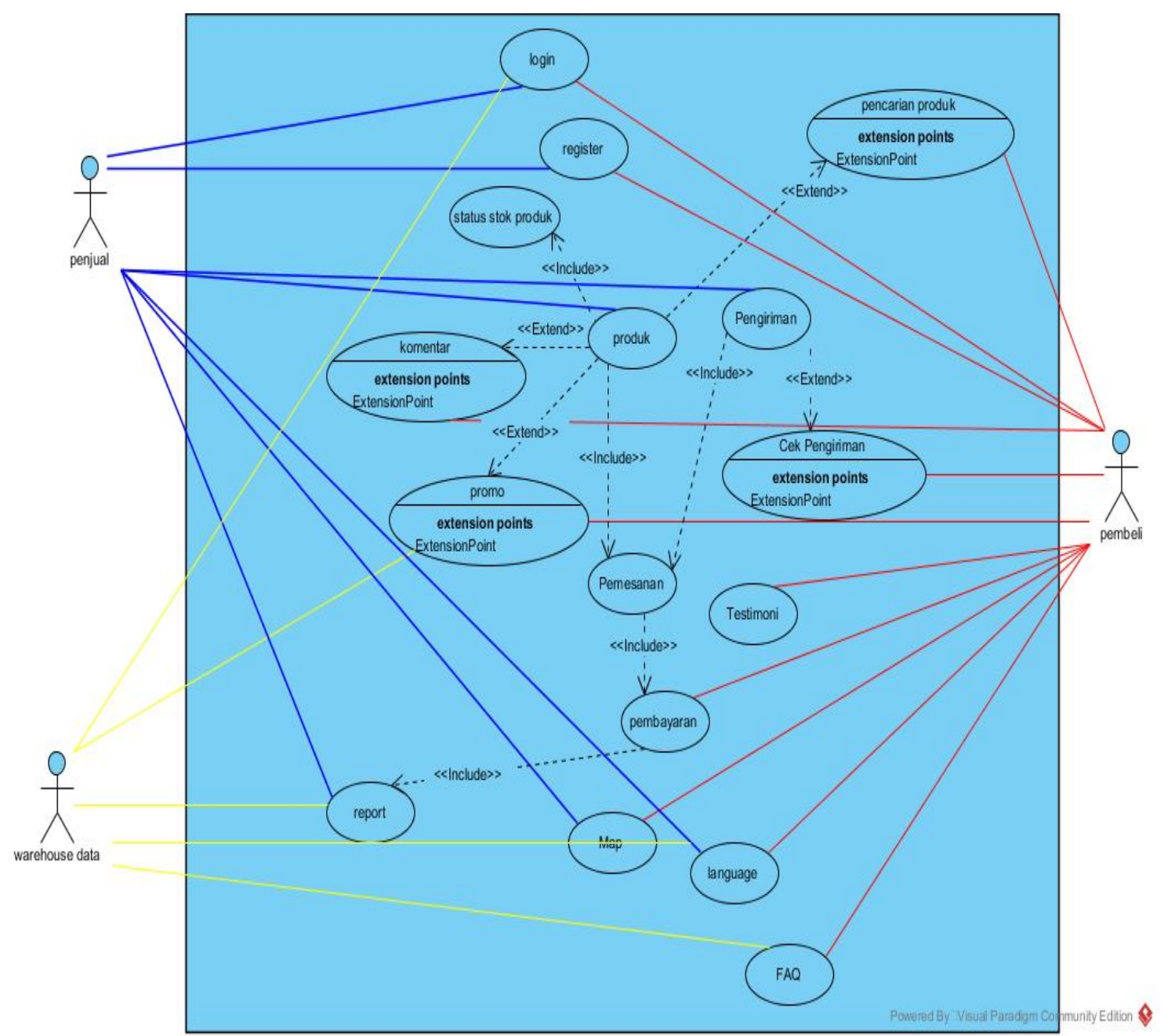

Gambar 5 Use Case Model Bisnis Micro Enterprise 
Jurnal Pseudocode, Volume IV Nomor 2, September 2017, ISSN 2355-5920 www.ejournal.unib.ac.id/index.php/pseudocode

Dari sudut pandang builder, proses sistem digambarkan menggunakan class diagram seperti yang terlihat pada Gambar 6.

Dari sudut pandang detailed representation berisi tentang uraian dari tabel yang telah digambarkan pada Gambar 6, sedangkan dari sudut pandang function enterprise menjelaskan fungsi dari tabel yang telah diuraikan pada detailed representation.

\section{B. Arsitektur Aplikasi (Kolom How)}

Menjelaskan tentang proses bisnis sistem dari sudut pandang Planner, Owner, Designer, Builder, Detailed Representation, dan Function Enterprise.
Dari sudut pandang planner proses sistem yang akan berjalan pada aplikasi mobile commerce yaitu proses aktivitas pembeli dan proses aktivitas penjual. Dari sudut pandang owner, yang terlibat pada proses jual beli yang ada pada sistem adalah penjual dan pembeli.

Dari sudut pandang designer akan dijelaskan proses aktivitas pembeli dan proses aktivitas penjual pada arsitektur mobile commerce yang diusulkan yang akan terlihat pada Gambar 7.

Pada sudut pandang detailed representation menjelaskan bagaimana alur sistem bekerja yang akan digunakan oleh user (Penjual, Pembeli), penjelasan lebih detil akan digambarkan pada sequence diagram pada Gambar 8.

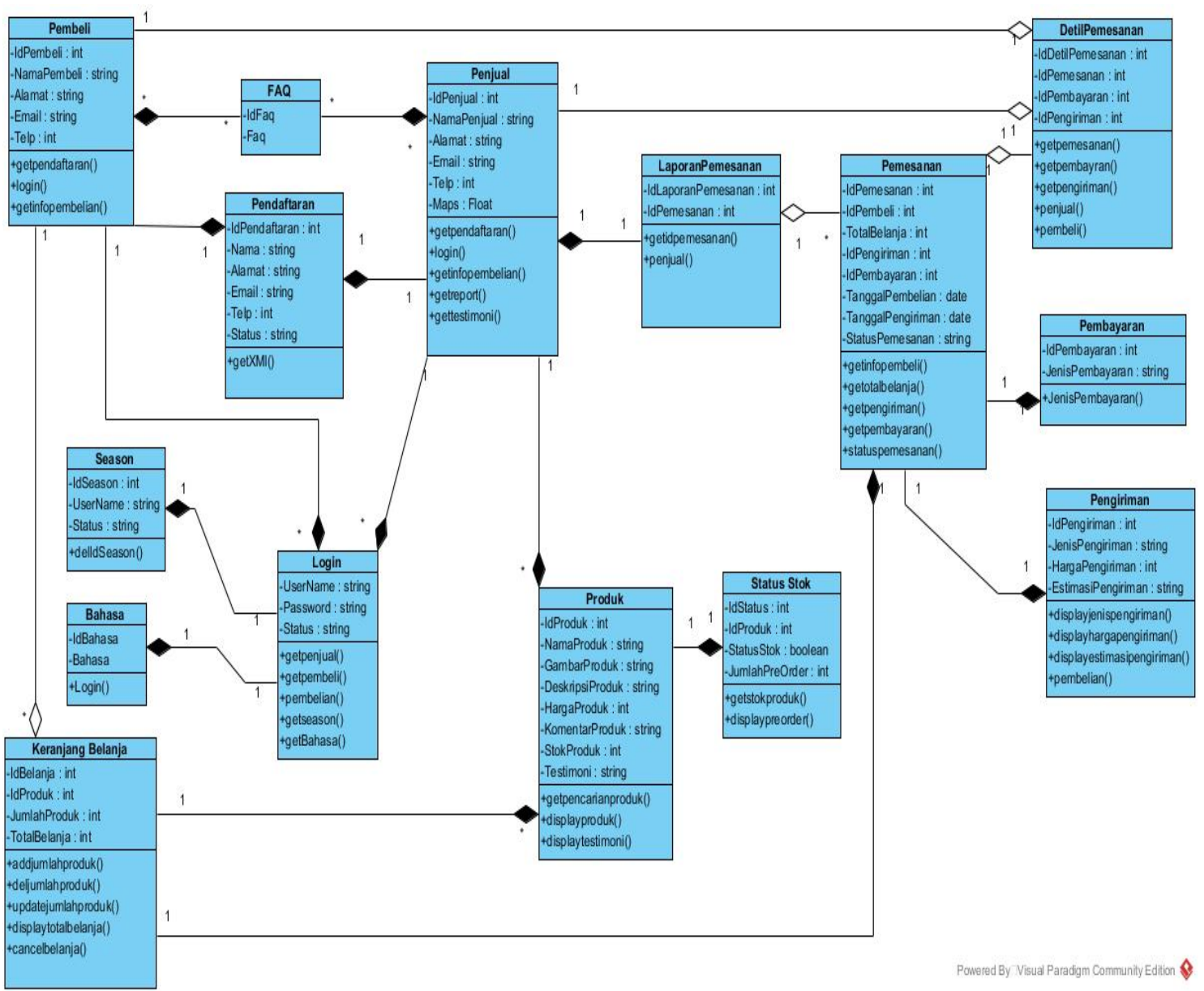

Gambar 6 Class Diagram Proses Bisnis 


\section{Jurnal Pseudocode, Volume IV Nomor 2, September 2017, ISSN 2355-5920 www.ejournal.unib.ac.id/index.php/pseudocode}

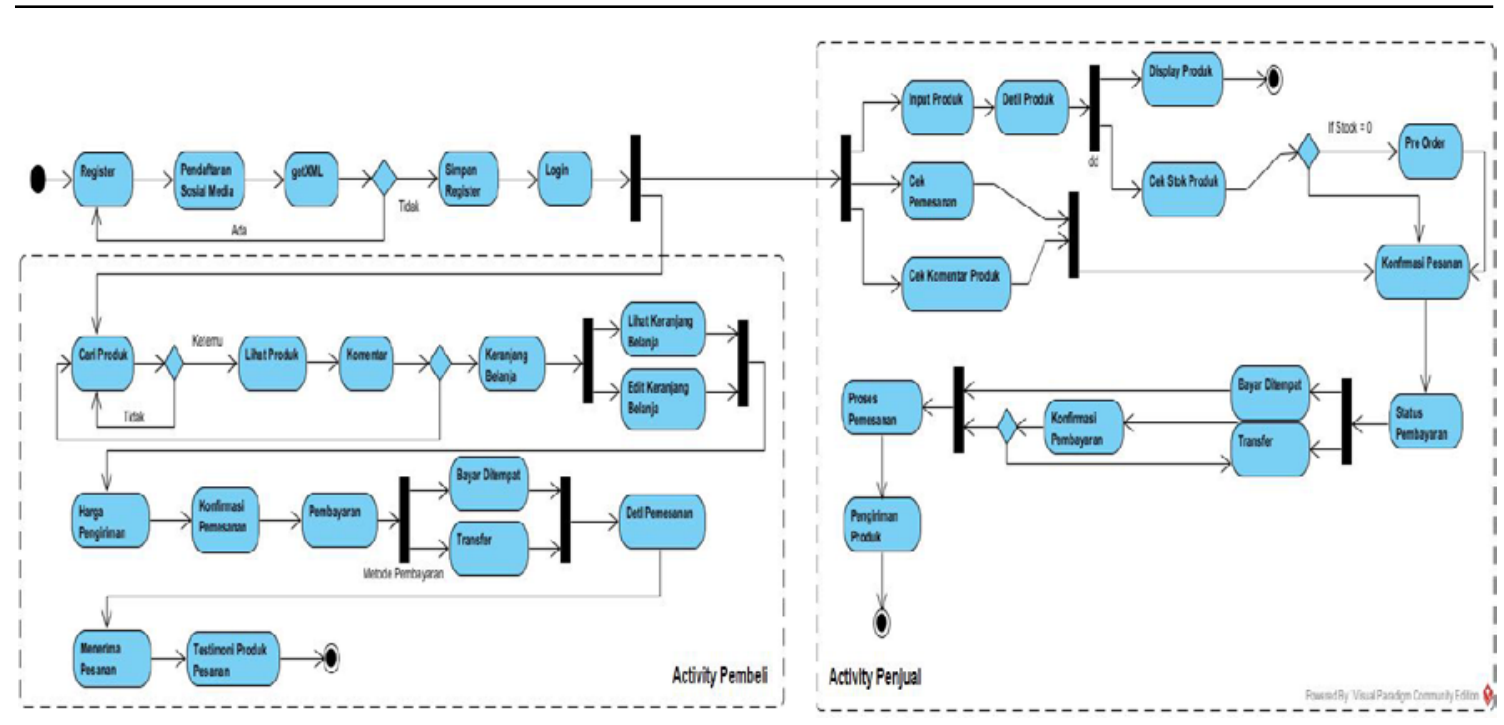

Gambar 7 Activity Diagram

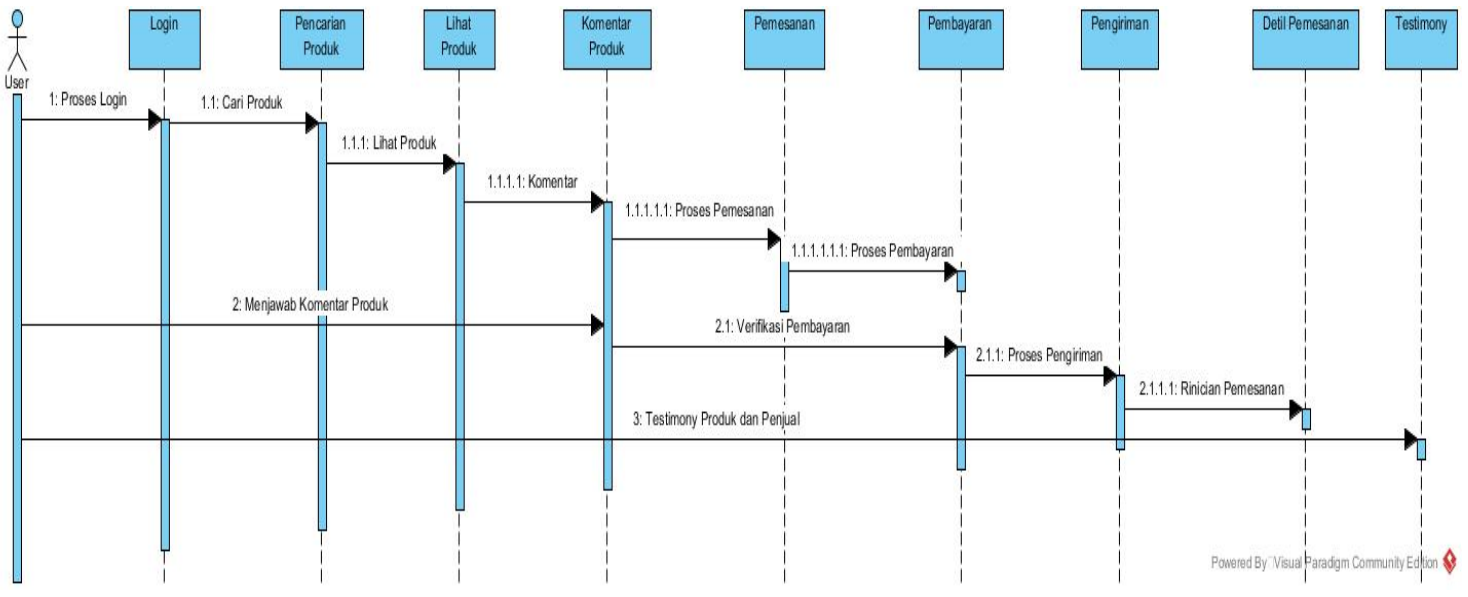

Gambar 8 Sequence Diagram Penggunaan Sistem

Pada sudut pandang function enterprise menjelaskan fitur-fitur yang akan didapat oleh pembeli dan penjual seperti yang terlihat pada Tabel 2.

Tabel 2. Daftar Fitur User

\begin{tabular}{|c|c|}
\hline User & Fitur \\
\hline \multirow[t]{9}{*}{ Penjual } & 1. Registrasi menggunakan akun sosial media \\
\hline & $(\mathrm{xml})$ \\
\hline & 2. Login untuk akses masuk \\
\hline & $\begin{array}{l}\text { 3. Produk : dapat menambahkan produk dan } \\
\text { jumlah stok pada produk yang akan dijual }\end{array}$ \\
\hline & $\begin{array}{l}\text { 4. Komentar : Menjawab pertanyaan seputar } \\
\text { produk oleh pembeli }\end{array}$ \\
\hline & Pemesanan : Melakukan proses pemesanan \\
\hline & produk yang telah disetujui \\
\hline & $\begin{array}{l}\text { 6. Konfirmasi Pembayaran : Cek apakah } \\
\text { pembayaran telah dilakukan oleh pembeli }\end{array}$ \\
\hline & $\begin{array}{l}\text { 7. Pengiriman : Melakukan autentifikasi } \\
\text { bahwa produk telah dikirimkan }\end{array}$ \\
\hline
\end{tabular}

\begin{tabular}{|c|cl|}
\hline User & \multicolumn{1}{|c|}{ Fitur } \\
\hline Pembeli & 1. & $\begin{array}{l}\text { Registrasi menggunakan akun sosial media } \\
\text { (xml) }\end{array}$ \\
& 2. & $\begin{array}{l}\text { Login untuk akses masuk } \\
\text { 3. }\end{array}$ \\
& $\begin{array}{l}\text { Pencarian Produk: Pembeli dapat } \\
\text { melakukan pencarian produk yang akan } \\
\text { dibeli }\end{array}$ \\
4. & $\begin{array}{l}\text { Komentar Produk : Pembeli dapat bertanya } \\
\text { tentang deskripsi produk. }\end{array}$ \\
5. & $\begin{array}{l}\text { Keranjang Belanja : Pembeli dapat melihat } \\
\text { detil pembelian beserta mengubah jumlah }\end{array}$ \\
& produk-produk yang akan dibeli. \\
6. & $\begin{array}{l}\text { Harga Pengiriman : Pembeli dapat melihat } \\
\text { estimasi pengiriman produk. }\end{array}$ \\
7. & $\begin{array}{l}\text { Pemayaran: Pembeli dapat memilih jenis } \\
\text { pembayaran yang dinginkan oleh pembeli } \\
\text { Detil Pemesanan : Pembeli dapat melihat } \\
\text { detil dari pemesanan yang dilakukan. }\end{array}$ \\
& 9. $\begin{array}{l}\text { Testimony : Pembeli dapat memberikan } \\
\text { komentar contoh tentang produk, } \\
\text { pengiriman untuk penjual }\end{array}$ \\
\hline
\end{tabular}


Jurnal Pseudocode, Volume IV Nomor 2, September 2017, ISSN 2355-5920 www.ejournal.unib.ac.id/index.php/pseudocode

\section{Arsitektur Teknologi (Kolom Where)}

Menjelaskan tentang definisi dari teknologi utama yang dibutuhkan untuk menyediakan dukungan lingkungan bagi aplikasi termasuk data yang akan dikelolanya dari sudut pandang Planner, Owner, Designer, Builder, Detailed Representation, dan Function Enterprise.

Pada sudut pandang planner dijelaskan perangkat yang akan digunakan yang tampak pada Tabel 3.

Tabel 3 Daftar Perangkat

\begin{tabular}{|l|l|}
\hline Perangkat & \multicolumn{1}{|c|}{ Kegunaan } \\
\hline $\begin{array}{l}\text { Mobile } \\
\text { Phone }\end{array}$ & $\begin{array}{l}\text { Digunakan untuk menjalankan aplikasi yang } \\
\text { akan digunakan }\end{array}$ \\
\hline $\begin{array}{l}\text { Main } \\
\text { Server }\end{array}$ & $\begin{array}{l}\text { Digunakan untuk menyimpan data setiap } \\
\text { transaksi jual beli }\end{array}$ \\
\hline
\end{tabular}

\begin{tabular}{|l|l|}
\hline Perangkat & Kegunaan \\
\hline $\begin{array}{l}\text { Akses } \\
\text { Data }\end{array}$ & $\begin{array}{l}\text { Digunakan untuk mengakses data antara } \\
\text { mobile phone dan server penyimpanan data }\end{array}$ \\
\hline \multicolumn{2}{c}{ Pada $\quad$ sudut pandang owner arsitektur }
\end{tabular}

networking akses jual beli yang telah berjalan saat ini. Dimana pelaku usaha micro enterprise masih menggunakan transaksi jual beli menggunakan social media seperti yang terlihat pada Gambar 9.

Pada sudut pandang designer menjelaskan bagaimana alur penjual dan pembeli mendapatkan aplikasi jual beli online yang terlihat pada Gambar 10 .

Pada sudut pandang builder ditampilkan Gambaran usulan tahapan model arsitektur teknologi ini dapat dilihat pada Gambar 11.
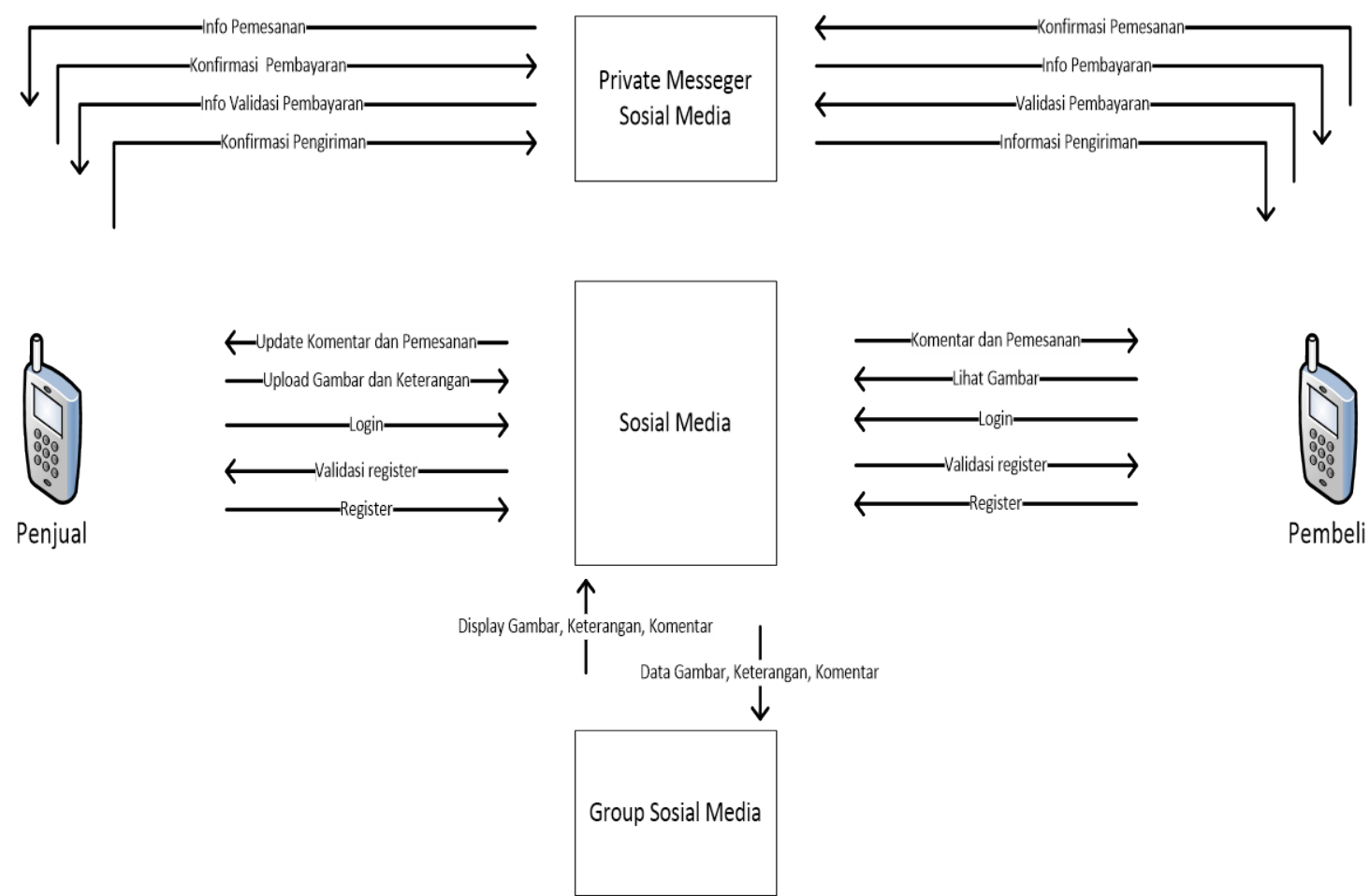

Pembeli 
Jurnal Pseudocode, Volume IV Nomor 2, September 2017, ISSN 2355-5920 www.ejournal.unib.ac.id/index.php/pseudocode

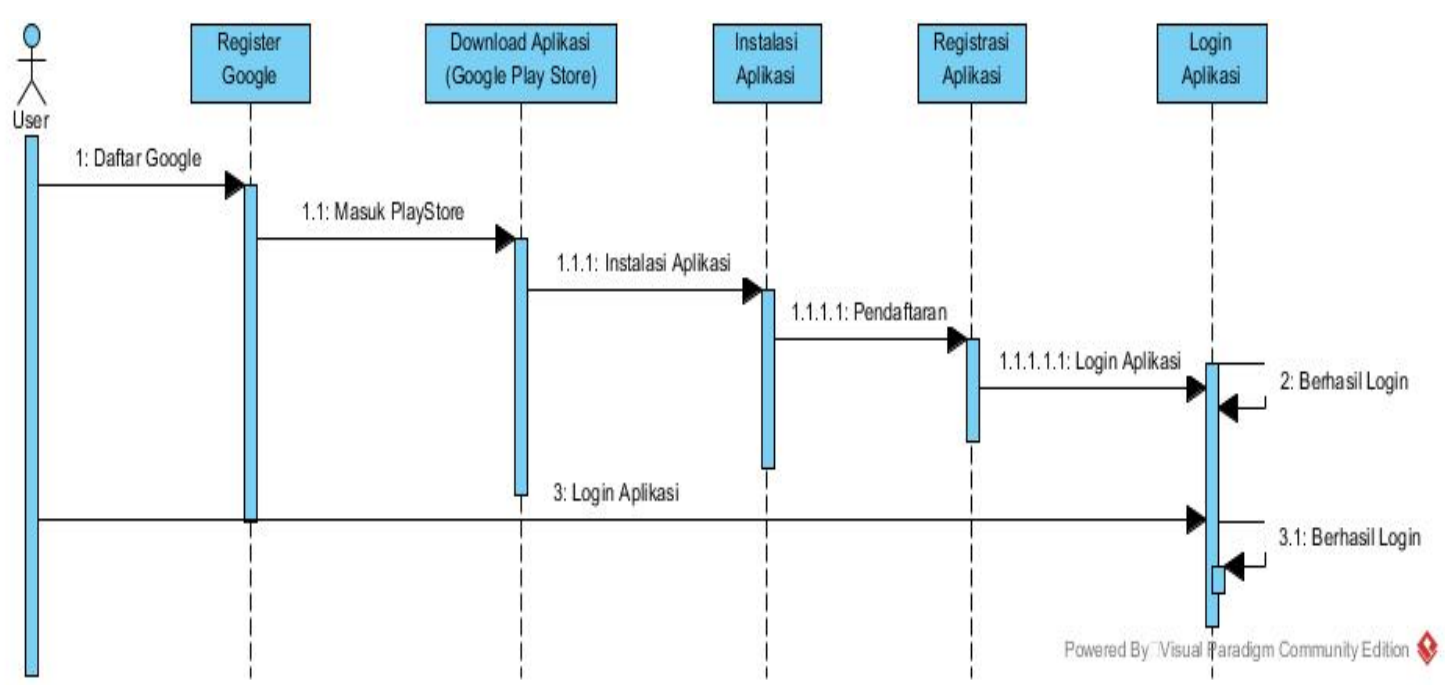

Gambar 10 Sequence Download Aplikas

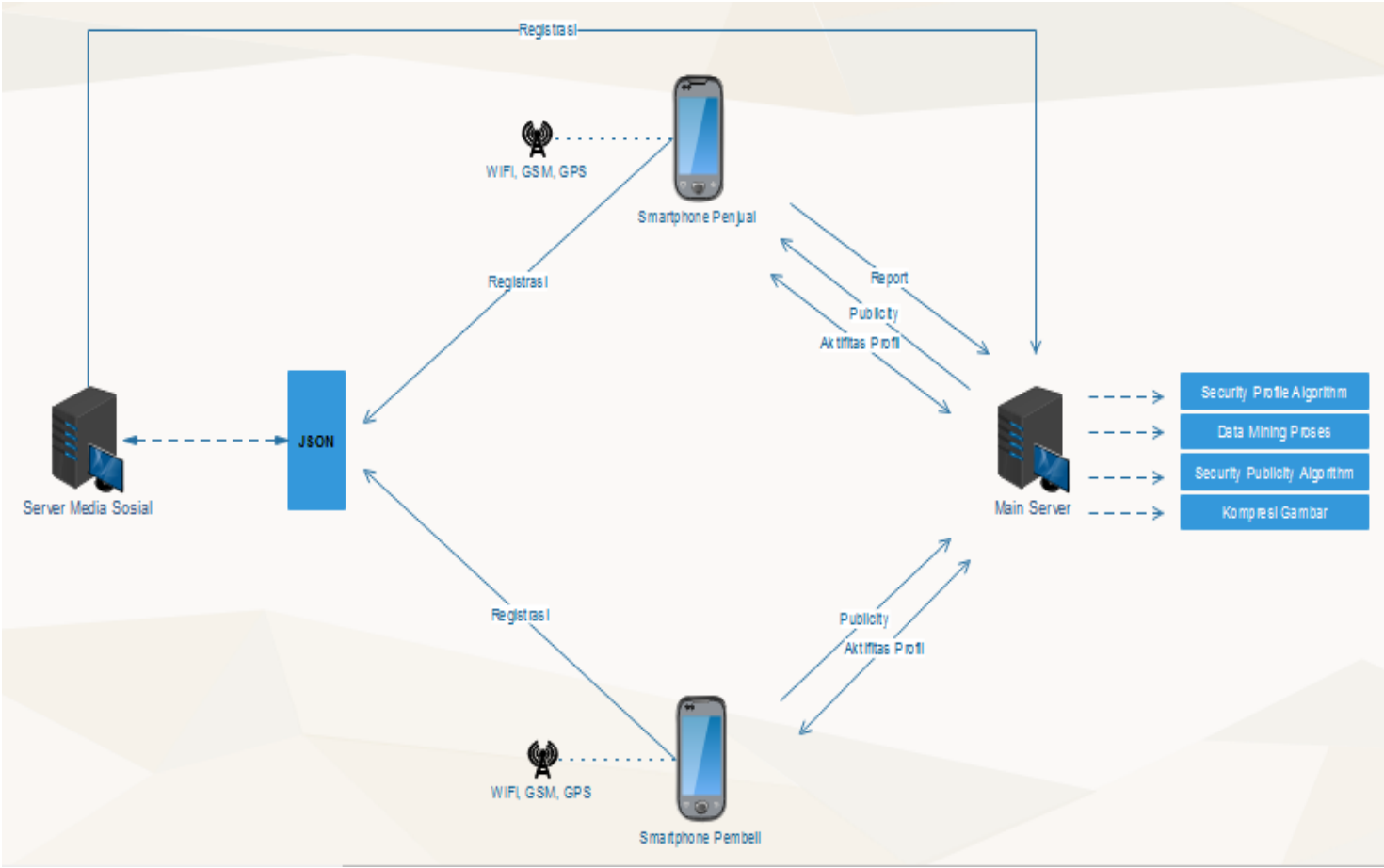

Gambar 11 Arsitektur Teknologi

Pada sudut pandang detailed representation berisi tentang penjelasan dari Gambar 11 bahwa semua proses jual beli akan dilakukan menggunakan mobile phone, sedangkan penyimpanan setiap proses jual beli akan dilakukan pada main server dimana semua layanan dan pengembangan sistem dilakukan oleh pihak main server. Pada pendaftaran terlihat bahwa arsitektur ini menggunakan teknologi JSON agar pihak micro enterprise lebih mudah untuk melakukan pendaftaran dimana usulan ini sesuai dengan hasil analysis content yang dilakukan pada tahapan sebelumnya.

Pada sudut pandang function enterprise membahas tentang rincian infrastruktur jaringan yang diperlukan untuk melakukan proses mobile commerce dari arsitektur yang diusulkan, seperti aplikasi mobile commerce yang membutuhkan 
akses internet untuk mengakses data pada main server, main server akan memberikan report setiap transaksi yang dilakuakn juga menyimpan semua transaksi yang dilakukan.

Pada main server diwajibkan mempunyai akses publik untuk semua aplikasi mobile yang telah dipasangkan pada pelaku usaha maupun pembeli dan juga menyertakan kompresi gambar dari setiap produk yang di jual oleh pihak micro enterprise agar akses data yang diperlukan tidak terlalu besar.

\section{Pengujian Kelayakan Arsitektur}

Pengujian kelayakan arsitektur dilakukan untuk mengetahui apakah arsitektur yang dibuat nantinya dapat diimplementasikan menjadi sebuah aplikasi mobile commerce untuk micro enterprise. Pengujian ini menggunakan metode EA Score Card untuk mengukur uji kelayakan kualitas kesiapan implementasi sebuah arsitektur.

Setelah tabel EA Score Card telah diisi lalu dilakukan perhitungan hasil pengujian dengan kriteria hasil pengujian yaitu:

a. Jika hasil pengujian kematangan arsitektur secara keseluruhan yang dicapai < 50\% maka arsitektur dinyatakan "Tidak Layak"

b. Jika hasil pengujian kematangan arsitektur secara keseluruhan yang dicapai > 50\% maka arsitektur dinyatakan “Layak”

\begin{tabular}{|c|c|c|}
\hline No & Responden & Validasi (\%) \\
\hline 1 & Responden A & 54,29 \\
\hline 2 & Responden B & 50,36 \\
\hline 3 & Responden C & 51,07 \\
\hline 4 & Responden D & 65,71 \\
\hline 5 & Responden E & 57,86 \\
\hline 6 & Responden F & 66,07 \\
\hline \multicolumn{2}{|c|}{ Overall Architectural Validasi } & 57,56 \\
\hline
\end{tabular}

*) Responden memiliki latar belakang sebagai pengembang software berbasis web dan mobile dan juga sebagai peneliti yang mengangkat tentang perkembangan aplikasi mobile
Dari hasil pengujian kelayakan arsitektur aplikasi mobile commerce untuk micro enterprise menggunakan EA Score Card yang tampak pada Tabel 4 dapat ditarik kesimpulan bahwa arsitektur aplikasi mobile commerce untuk micro enterprise dinyatakan layak dengan hasil pengujian sebesar $57,56 \%$.

\section{KESIMPULAN DAN SARAN}

\section{A. Kesimpulan}

Berdasarkan pada penjelasan yang telah dipaparkan maka dapat diperoleh kesimpulan sebagai berikut:

1. Pemodelan arsitektur mobile commerce untuk micro enterprise dilakukan dengan menggunakan Enterprise Architecture Planning berbasis Zachman Framework dari hasil content analysis data dari 33 sampel yang dikumpulkan melalui teknik wawancara. Pemodelan kemudian diuji menggunakan Enterprise Architecture Score Card (EA Score Card).

2. Pemodelan arsitektur mobile commerce dipetakan menjadi arsitektur data, arsitektur aplikasi dan arsitektur teknologi. Komponen utama arsitektur data yang berhasil terindentifikasi antara lain data pembeli, data penjual dan data transaksi. Komponen arsitektur aplikasi terdiri dari 16 fitur utama yang dapat diakses oleh penjual dan pembeli. Tujuh fitur untuk penjual antara lain registrasi, login, produk, komentar, pemesanan, konfirmasi pembayaran, dan pengiriman. Sembilan fitur untuk pembeli antara lain, registrasi, login, pencarian produk, komentar produk, keranjang belanja, harga pengiriman, pembayaran, detil pemesanan dan testimoni. Untuk komponen arsitekur teknologi 
melibatkan perangkat mobile phone, main

server dan server media sosial.

3. Pengujian model arsitektur dilakukan oleh enam responden dengan menggunakan

Enterprise Architecture Score Card (EA Score

Card) dengan hasil perhitungan 57,56\% yang berarti arsitektur tersebut dinyatakan layak.

B. Saran

Adapun saran untuk kelanjutan penelitian antara lain:

1. Penelitian yang dilakukan hanya terbatas pada metode EAP layer 1 hingga 3 yang sebaiknya dilakukan hingga layer 4 agar diketahui rencana pencapaian atau implementasi jangka panjang.

2. Penelitian selanjutnya memungkinkan untuk melanjutkan pada kolom matrik Zachman framework bertujuan mendapatkan hasil prototype sistem yang akan diimplementasikan.

\section{REFERENSI}

[1] Badan Pusat Statistik Provinsi Bengkulu, "Pertumbuhan Produksi Industri Mikro dan Kecil (IMK) Provinsi Bengkulu,” 2013. [Online]. Available: http://bengkulu.bps.go.id/linkTabelStatis/view/id/115. [Accessed: 04-Apr-2017].

[2] Dinas Koperasi dan UMKM Kota Bengkulu, "Laporan Hasil Pendataan Usaha Mikro Kecil dan Menengah Tahun Anggaran 2016 di Kota Bengkulu,” 2016.

[3] I. Mutmainah, "Effectiveness of Empowerment Micro Enterprise Efektivitas Pemberdayaan Usaha Mikro,” vol. 16, no. 1, pp. 85-101, 2015.

[4] R. Sudaryanto and R. R. Wijayanti, "Strategi Pemberdayaan UMKM Menghadapi Pasar Bebas Asean. Pusat Kebijakan Ekonomi Makro,” Jakarta, 2013.

[5] W. Hao and X. Yue, "The Study on the Application of ECommerce in Small and Medium-sized Enterprises,” in 2010 Interntional Conference on Computer and Communication Technologies in Agriculture Engineering, 2010, pp. 500-503.

[6] J. Wang, J. Jiang, and F. He, "Problem and Countermeasure on the Development of Mobile Electronic Commerce in China Main Problems Faced of Mobile Electronic Commerce," in Instrumentation, Measurement, Circuits and Systems, T. Zhang, Ed. Springer Berlin Heidelberg, 2012, pp. 861-866.

[7] S. R. Wardani and A. Hidayat, "Perancangan Electronic Commerce Sebagai Media Promosi Dan Penjualan Berbasis Mobile,” pp. 43-56, 2012.
[8] J. Donner, "Microentrepreneurs and Mobiles: An Exploration of the Uses of Mobile Phones by Small Business Owners in Rwanda,” 2005, vol. 2, no. 1, pp. 121.

[9] E. Setiawan, "Perancangan Arsitektur Sistem Informasi Enterprise Menggunakan Kerangka Zachman pada PT. Sumber Buana Motor,” pp. 248-254, 2016.

[10] V. Kolici, V. Segu, and L. Barolli, “Analysis of Mobile and Web Applications in Small and Medium Size Enterprises," in 2013 Eighth International Conference on P2P, Parallel, Grid, Cloud and Internet Computing, 2013, pp. 324-330.

[11] Yunis, R., Surendro, K., and E. S. Panjaitan, "Pengembangan Model Arsitektur Enterprise Untuk Perguruan Tinggi,” JUTI J. Ilm. Teknol. Inf., vol. 8, no. 1, 2010.

[12] J. Schekkerman, "Trends in Enterprise Architecture," 2005. 